\title{
Prevalence and risk factors of impaired fasting glucose and diabetes among Chinese children and adolescents: a national observational study
}

\author{
Zhenghe Wang ${ }^{1}$, Zhiyong Zou ${ }^{1}$, Haijun Wang ${ }^{2}$, Jin Jing $^{3}$, Jiayou Luo ${ }^{4}$, Xin Zhang ${ }^{5}$, Chunyan Luo ${ }^{6}$, \\ Haiping Zhao ${ }^{7}$, Dehong Pan ${ }^{8}$, Jun $\mathrm{Ma}^{1}$, Bin Dong ${ }^{1 *}$ and Yinghua Ma ${ }^{1}$ * \\ ${ }^{1}$ Institute of Child and Adolescent Health, School of Public Health, Peking University, Beijing 100191, People's \\ Republic of China \\ ${ }^{2}$ Department of Maternal and Child Health, School of Public Health, Peking University, Beijing 100191, People's \\ Republic of China \\ ${ }^{3}$ Department of Maternal and Child Health, School of Public Health, Sun Yat-sen University, Guangzhou 510000, \\ People's Republic of China \\ ${ }^{4}$ Department of Maternal and Child Health, School of Public Health, Central South University, Changsha 410083, \\ People's Republic of China \\ ${ }^{5}$ School of Public Health, Tianjin Medical University, Tianjin 300072, People's Republic of China \\ ${ }^{6}$ Shanghai Municipal Center for Disease Control and Prevention, Shanghai 201404, People's Republic of China \\ ${ }^{7}$ School of Public Health, Ningxia Medical University, Yinchuan 750004, People's Republic of China \\ ${ }^{8}$ Liaoning Health and Family Planning Inspection, Shenyang 110005, People's Republic of China
}

(Submitted 25 December 2017 - Final revision received 3 June 2018 - Accepted 26 June 2018 - First published online 29 August 2018 )

\section{Abstract}

The prevalence of impaired fasting glucose (IFG) and diabetes mellitus (DM) has reportedly increased significantly among Chinese children and adolescents. We aimed to examine the prevalence of IFG and DM, the disparities in sex and region and related risk factors among Chinese children and adolescents. A total of 16434 Chinese children aged 6-17 years were selected from a national cross-sectional survey, and fasting glucose was measured for all participants. Overall, mean fasting plasma glucose (FPG) concentration was (4.64 (sD 0.51)) mmol/l, and the prevalence of DM and IFG was 0.10 and $1.89 \%$, respectively. Compared with girls, boys had higher FPG concentration $(4.69 v .4 .58 \mathrm{mmol} / \mathrm{l}, r 0 \cdot 107, P<0.001)$ and IFG prevalence $\left(2.67 v .1 .07 \%, r_{\varphi} 0.059, P<0.001\right)$. Compared with rural children and adolescents, urban children and adolescent had higher FPG concentration ( $4.65 v .4 .62 \mathrm{mmol} / \mathrm{l}, r 0.029, P<0.001)$ and DM prevalence $\left(0.15 v .0 .05 \%, r_{\varphi} 0.016, P<0.01\right)$. In addition, self-reported fried foods intake and overweight/obesity were positively associated with IFG, and the proportion of consuming fried foods more than or equal to once per week and overweight/obesity prevalence in boys and urban children and adolescents were significantly higher than girls and rural children and adolescents, respectively $(P<0 \cdot 05)$. Although the prevalence of IFG and DM was relatively low in Chinese children and adolescents, sex and region disparities were observed, which may be associated with differences in overweight/obesity prevalence and dietary factors.

Key words: Disparities: Diabetes: Obesity: Epidemiology: Impaired fasting glucose

Type 2 diabetes mellitus (T2DM) in adolescence is rapidly becoming one of the new worldwide public health challenges of the 21st century ${ }^{(1)}$. According to the report of International Diabetes Federation, the number of Chinese people with diabetes ranks first (109.6 million) in the world, and the sharply increasing onset of diabetes in children is a matter of great concern $^{(2)}$. T2DM was rarely seen in children 20 years ago, however this has changed due to increasing detection, rising obesity and sedentary lifestyle ${ }^{(3)}$. Increasing T2DM prevalence in children and adolescents has been observed in developed and developing countries ${ }^{(3-7)}$. Meanwhile, as one of the important indicators of altered glucose metabolism, impaired fasting glucose (IFG) has been an emerging issue in children and adolescents over the past three decades ${ }^{(8)}$. It has been suggested that IFG in childhood significantly increases their later risk of $\mathrm{T} 2 \mathrm{DM}$ and $\mathrm{CVD}^{(9)}$.

$\mathrm{Fu}$ et $a l^{\left({ }^{(6)}\right.}$ observed the prevalence of diabetes and prediabetes in boys was significant higher than in girls. But their results are still controversial. Other studies conducted in Chinese children did not observe that sex difference ${ }^{(10)}$. Moreover, these two studies observed the diabetes prevalence in high socioeconomic regions seemed to be greater than regions with low

Abbreviations: DM, diabetes mellitus; FPG, fasting plasma glucose; IFG, impaired fasting glucose; T2DM, type 2 diabetes mellitus.

* Corresponding authors: B. Dong, fax +8610 82801178, email bindong@bjmu.edu.cn; Y. Ma, email yinghuama@bjmu.edu.cn 
socio-economic level ${ }^{(6,10)}$. However, it remains unknown what led to these differences. With limited medical resources ${ }^{(11)}$, it is of great significance to prioritise intervention on the critical factors contributing to these differences for reducing the burden of diabetes and improving health in childhood.

In view of these, using data of a Chinese national survey, the present study investigated the prevalence of diabetes mellitus (DM) and IFG, and the disparities in sex and region, among children and adolescents aged 6-17 years, and further explored potential factors contributing to these gaps.

\section{Methods \\ Study design and population}

A national multicentred school-based health lifestyles intervention against obesity was performed from September 2013 to June 2014. The details of the programme have been described elsewhere ${ }^{(12)}$. The programme involved participants aged 6-18 years from ninety-four primary and secondary schools in seven provinces in China, including Chongqing, Hunan, Guangdong, Liaoning, Ningxia, Shanghai and Tianjin, and a total of 16746 blood samples were collected. In the present study, participants aged $6-17$ years were included ( $n$ 16 633), however those with extremely low concentration of fasting plasma glucose (FPG, $<3.0 \mathrm{mmol} / \mathrm{l}$ ) ( $n$ 171) or missing records of height or weight ( $n$ 28) were excluded. As a result, 16434 participants were involved into the final analysis.

\section{Ethnic statements}

This study was approved by the Medical Ethical Committee of Peking University Health Science Center (IRB00001052-13034), and written informed consents were obtained from all the children and their parents.

\section{Data collection and measurements}

All investigators in this programme were trained to measure and record relevant information utilising standardised procedures. Self-reported information of participants' demographic characteristics, dietary behaviour, physical activity and family history of DM (defined as the presence of DM in at least one parent or grandparent) was collected through questionnaires. FFQ was used to collect the intake frequencies of fruit, vegetables, sweet beverages, meats, fried foods and milk in the past $7 \mathrm{~d}$. The threshold of two servings per $d$ was used to categorise fruit (about $200 \mathrm{~g}$ per serving) and vegetables (about $150 \mathrm{~g}$ per serving) intake, and threshold of one serving per $\mathrm{d}$ was used to categorise meats (about $100 \mathrm{~g}$ per serving) and milk (about $250 \mathrm{ml}$ per serving) intake. Questionnaire was also used to collect information of sedentary time, which included time of being seated or lying $1 \mathrm{~d}$ divided into two groups. The International Physical Activity Questionnaire Short Form was used to assess physical activity level, which was categorised into three groups (light, moderate and vigorous physical activity) ${ }^{(13)}$.

The anthropometric measurements were collected. Height and weight were measured according to a standardised procedure. A portable stadiometer (model TZG; Jiangyin Hongya Science and Education Equipment Co., Ltd) was used to measure height, and a scale (model RGT-140; Wuxi Weighing Apparatus Factory Co., Ltd) was used to measure fasting body weight. Participants were asked to wear underclothes only and to stand straight without shoes. Height is accurate to $0.1 \mathrm{~cm}$ and weight to $0 \cdot 1 \mathrm{~kg}$. Both height and weight were measured twice and the average values were used to calculate the BMI (weight/ height $^{2}, \mathrm{~kg} / \mathrm{m}^{2}$ ).

\section{Laboratory tests}

Venous blood samples were collected after $8 \mathrm{~h}$ of overnight fasting. Fasting glucose was tested by a qualified biomedical analyses company using glucose oxidase method.

\section{Definitions}

The recommendations of American Diabetes Association ${ }^{(14)}$ were used to define IFG and DM. A FPG concentration of $\geq 126 \mathrm{mg} / \mathrm{dl}(7.0 \mathrm{mmol} / \mathrm{l})$ was defined as DM, while an FPG between 100 and $125 \mathrm{mg} / \mathrm{dl}(5 \cdot 6-6 \cdot 9 \mathrm{mmol} / \mathrm{l})$ was classified as IFG, and glucose $<5.6 \mathrm{mmol} / \mathrm{l}$ was defined as normal.

The Chinese BMI percentile criterion for screening overweight and obesity in children and adolescents was used to define the overweight and obesity among students aged 6-17 years ${ }^{(15,16)}$. Participants with age- and sex-specific BMI $\geq 95$ th percentile were defined as obesity, while those with age- and sex- specific 85 th $\leq$ BMI $<95$ th were defined as overweight $^{(15,16)}$

According to the recommendation of WHO on the age ranges of children and adolescents, the threshold of 10 years old was used to categorise the participants aged $6-17$ years into children (6-9 years) and adolescents (10-17 years) ${ }^{(17)}$.

\section{Statistical analysis}

Statistical analysis was performed with SPSS 20.0 (IBM Corporation). The WHO growth chart (2007) was used to calculate $z$-scores for height, weight and BMI ${ }^{(18)}$. Dunnett's test was used to compare the differences for continuous variables, and Cohen's $d$ equation was used to calculate effect size $(r)$. The $\chi^{2}$ test was used to compare the differences for proportions, and the $\varphi$ coefficient $\left(r_{\varphi}\right)$ was used to calculate effect size. The Wilson method was used to estimate $95 \%$ CI since the prevalence estimates were close to zero ${ }^{(19)}$. A logistics regression model with the backward likelihood ratio method was used to explore the influencing factors of IFG. A two-sided $P<0.05$ was considered as statistical significance.

\section{Results}

\section{Characteristics of study population}

A total of 8393 (51.1\%) boys and 8041 (48.9\%) girls aged 6-17 years participated in the study. Compared with boys, girls had lower BMI and FPG, reported higher frequency of fruit intake and lower frequencies of fried foods, milk, meats and 
carbonated beverages intake $(P<0 \cdot 05$, Table 1$)$. However, boys reported less frequently a family history of diabetes and sedentary time than girls $(P<0 \cdot 05$, Table 1$)$.

\section{Sex and age disparities in prevalence of impaired fasting} glucose and diabetes mellitus

The overall prevalence of IFG and DM was 1.89 (95\% CI 1.67 , $2 \cdot 08$ ) and $0 \cdot 10(95 \%$ CI $0 \cdot 05-0 \cdot 15) \%$, respectively (Table 2 ).

Compared with girls, boys had higher FPG concentration and IFG prevalence in total population and in all age subgroups $(P<0 \cdot 001$, Table 2$)$. However, this study did not observe any statistically significant difference in DM prevalence between boys and girls ( $P>0.05$, Table 2$)$.

Compared with children, adolescents had higher IFG prevalence $\left(2.26 v .1 .30 \%, r_{\varphi} 0.034, P<0.05\right)$ in boys $(3.13 v$. $\left.1.94 \%, r_{\varphi} 0.036, P<0.05\right)$ and girls $\left(1.34 v .0 .66 \%, r_{\varphi} 0.032\right.$, $P<0.05)$. Similarly, adolescents had higher FPG concentration than children $(4.65 v .4 .61 \mathrm{mmol} / 1, r 0.040, P<0.01)$ in girls ( $4.60 v .4 .54 \mathrm{mmol} / 1, r 0.063, P<0.01$ ), but not in boys ( $4.70 v$. $4.68 \mathrm{mmol} / 1, r 0.019, P>0.05)$. However, the difference of DM prevalence was not statistically significant between children and adolescents $(P>0 \cdot 05$, Table 2$)$.

Region disparities in prevalence of impaired fasting glucose and diabetes mellitus

Overall, compared with rural population, urban population had higher FPG concentration (4.65 v. $4.62 \mathrm{mmol} / 1, \quad r \quad 0.029$, $P<0.001)$ and DM prevalence (0.15 v. $0.05 \%, r_{\varphi} 0.016, P<0.01$, Table 3). After stratification by age subgroups, only urban adolescents had a higher FPG concentration than their rural

Table 1. Characteristics of the Chinese children and adolescents aged 6-17 years

(Numbers and percentages; mean values and standard deviations)

\begin{tabular}{|c|c|c|c|c|c|c|c|}
\hline \multirow[b]{2}{*}{ Variables } & \multicolumn{2}{|c|}{ Total } & \multicolumn{2}{|c|}{ Boys } & \multicolumn{2}{|c|}{ Girls } & \multirow[b]{2}{*}{$P$} \\
\hline & $n$ & $\%$ & $n$ & $\%$ & $n$ & $\%$ & \\
\hline Age & & & & & & & 0.565 \\
\hline Mean & $11 \cdot 1$ & & $11 \cdot 1$ & & $11 \cdot 1$ & & \\
\hline $\mathrm{SD}$ & 3.3 & & $3 \cdot 2$ & & 3.3 & & \\
\hline Height (cm) & & & & & & & $<0.001$ \\
\hline Mean & $147 \cdot 2$ & & $148 \cdot 8$ & & 145.5 & & \\
\hline SD & $17 \cdot 0$ & & $18 \cdot 3$ & & $15 \cdot 2$ & & \\
\hline Height $z$-score & & & & & & & $<0.001$ \\
\hline Mean & $0 \cdot 21$ & & 0.28 & & 0.14 & & \\
\hline SD & 1.03 & & 1.04 & & 1.00 & & \\
\hline Weight (kg) & & & & & & & $<0.001$ \\
\hline Mean & 41.9 & & $43 \cdot 6$ & & $40 \cdot 1$ & & \\
\hline SD & $15 \cdot 7$ & & $17 \cdot 2$ & & $13 \cdot 8$ & & \\
\hline Weight z-score & & & & & & & $<0.001$ \\
\hline Mean & 0.46 & & 0.63 & & 0.28 & & \\
\hline $\mathrm{SD}$ & 1.25 & & 1.34 & & $1 \cdot 13$ & & \\
\hline BMI $\left(\mathrm{kg} / \mathrm{m}^{2}\right)$ & & & & & & & $<0.001$ \\
\hline Mean & $18 \cdot 65$ & & $18 \cdot 95$ & & $18 \cdot 34$ & & \\
\hline $\mathrm{SD}$ & 3.8 & & 3.98 & & 3.58 & & \\
\hline BMI z-score & & & & & & & $<0.001$ \\
\hline Mean & 0.17 & & 0.33 & & 0.01 & & \\
\hline SD & $1 \cdot 27$ & & $1 \cdot 38$ & & $1 \cdot 12$ & & \\
\hline FPG (mmol/l) & & & & & & & $<0.001$ \\
\hline Mean & $4 \cdot 64$ & & 4.69 & & 4.58 & & \\
\hline $\mathrm{SD}$ & 0.51 & & 0.53 & & 0.49 & & \\
\hline Sedentary time $(\mathrm{h} / \mathrm{d})$ & & & & & & & 0.025 \\
\hline Mean & $9 \cdot 63$ & & $9 \cdot 56$ & & $9 \cdot 71$ & & \\
\hline SD & 3.67 & & 3.68 & & 3.67 & & \\
\hline Urban & 8012 & $48 \cdot 8$ & 4458 & $53 \cdot 1$ & 3554 & $44 \cdot 2$ & $<0.001$ \\
\hline Family history of diabetes & 3040 & $18 \cdot 5$ & 1475 & $17 \cdot 6$ & 1565 & $19 \cdot 5$ & 0.002 \\
\hline Fruit intake $<300 \mathrm{~g} / \mathrm{d}$ & 10960 & $79 \cdot 6$ & 5521 & $80 \cdot 4$ & 5439 & $78 \cdot 9$ & 0.027 \\
\hline Vegetables consumption $<400 \mathrm{~g} / \mathrm{d}$ & 10936 & $80 \cdot 0$ & 5485 & $80 \cdot 4$ & 5451 & $79 \cdot 5$ & 0.191 \\
\hline Carbonated beverages intake $\geq$ once/week & 6481 & $47 \cdot 2$ & 3321 & 48.5 & 3160 & $45 \cdot 9$ & 0.002 \\
\hline Meats consumption $\geq 100 \mathrm{~g} / \mathrm{d}$ & 1829 & $13 \cdot 3$ & 961 & $14 \cdot 1$ & 868 & $12 \cdot 6$ & 0.013 \\
\hline Fried foods intake $\geq$ once/week & 6421 & $46 \cdot 6$ & 3267 & $47 \cdot 5$ & 3154 & $45 \cdot 7$ & 0.028 \\
\hline Milk consumption $<250 \mathrm{ml} / \mathrm{d}$ & 10224 & $74 \cdot 1$ & 5034 & $73 \cdot 1$ & 5190 & $75 \cdot 0$ & 0.013 \\
\hline Physical activity level & & & & & & & 0.440 \\
\hline Light PA & 12088 & $73 \cdot 6$ & 6145 & $73 \cdot 2$ & 5943 & 73.9 & \\
\hline Moderate PA & 3292 & $20 \cdot 0$ & 1714 & $20 \cdot 4$ & 1578 & $19 \cdot 6$ & \\
\hline Vigorous PA & 1054 & 6.4 & 534 & 6.4 & 520 & $6 \cdot 5$ & \\
\hline BMI group & & & & & & & $<0.001$ \\
\hline Normal weight & 12814 & $78 \cdot 0$ & 6145 & $73 \cdot 2$ & 6669 & 82.9 & \\
\hline Overweight & 1991 & $12 \cdot 1$ & 1216 & 14.5 & 775 & $9 \cdot 6$ & \\
\hline Obesity & 1629 & 9.9 & 1032 & $12 \cdot 3$ & 597 & $7 \cdot 4$ & \\
\hline
\end{tabular}

FPG, fasting plasma glucose; PA, physical activity. 
Table 2. Fasting glucose level (mmol/l) and prevalence of impaired fasting glucose (IFG) in Chinese children, stratified by sex and age group

(Mean values and standard deviations; numbers, percentages and $95 \%$ confidence intervals)

\begin{tabular}{|c|c|c|c|c|c|c|c|c|c|}
\hline \multirow[b]{2}{*}{ Age group } & \multirow[b]{2}{*}{$n$} & \multicolumn{2}{|c|}{ FPG } & \multicolumn{3}{|c|}{ IFG prevalence } & \multicolumn{3}{|c|}{ DM prevalence } \\
\hline & & Mean & SD & $n$ & $\%$ & $95 \% \mathrm{Cl}$ & $n$ & $\%$ & $95 \% \mathrm{Cl}$ \\
\hline \multicolumn{10}{|l|}{ Boys } \\
\hline 6-9 years & 3255 & $4 \cdot 68^{\star \star \star}$ & 0.47 & 63 & $1.94^{\star \star \star}$ & $1.46,2.41$ & 3 & 0.09 & $0.00,0.20$ \\
\hline $10-17$ years & 5138 & $4 \cdot 70^{\star \star \star}$ & 0.57 & 161 & $3 \cdot 13^{\star \star \star} \dagger$ & $2 \cdot 66,3 \cdot 61$ & 8 & 0.16 & $0.05,0.26$ \\
\hline 6-17 years & 8393 & $4 \cdot 69^{\star \star \star}$ & 0.53 & 224 & $2 \cdot 67^{\star \star \star}$ & $2 \cdot 32,3 \cdot 01$ & 11 & $0 \cdot 13$ & $0.05,0.21$ \\
\hline \multicolumn{10}{|l|}{ Girls } \\
\hline $6-9$ years & 3192 & 4.54 & 0.43 & 21 & 0.66 & $0.38,0.94$ & 1 & 0.03 & $0.00,0.09$ \\
\hline $10-17$ years & 4849 & 4.60†† & 0.52 & 65 & $1.34 \dagger$ & $1.02,1.67$ & 5 & 0.10 & $0.01,0.19$ \\
\hline 6-17 years & 8041 & 4.58 & 0.49 & 86 & 1.07 & $0.84,1.29$ & 6 & 0.08 & $0.02,0.13$ \\
\hline \multicolumn{10}{|l|}{ Both sexes } \\
\hline $6-9$ years & 6447 & $4 \cdot 61$ & 0.45 & 84 & 1.30 & $1.03,1.58$ & 4 & 0.06 & $0.00,0.12$ \\
\hline $10-17$ years & 9987 & 4.65†† & 0.55 & 226 & 2.26†† & $1.97,2.56$ & 13 & 0.13 & $0.06,0.20$ \\
\hline $6-17$ years & 16434 & 4.64 & 0.51 & 308 & 1.89 & $1.67,2.08$ & 17 & 0.10 & $0.05,0.15$ \\
\hline
\end{tabular}

DM, diabetes mellitus; FPG, fasting plasma glucose.

*** $P<0.001$ between boys and girls.

$\dagger P<0.05$ between 6-9 years group and 10-17 years group; $\dagger \dagger P<0.01$ between $6-9$ years group and 10-17 years group.

Table 3. Differences in mean level of fasting glucose ( $\mathrm{mmol} / \mathrm{l})$ and prevalence of impaired fasting glucose (IFG) between urban and rural children

(Mean values and standard deviations; numbers, percentages and $95 \%$ confidence intervals)

\begin{tabular}{|c|c|c|c|c|c|c|c|c|c|}
\hline \multirow[b]{2}{*}{ Region } & \multirow[b]{2}{*}{$n$} & \multirow[b]{2}{*}{ Mean } & \multirow[b]{2}{*}{ SD } & \multicolumn{3}{|c|}{ IFG prevalence } & \multicolumn{3}{|c|}{ DM prevalence } \\
\hline & & & & $n$ & $\%$ & $95 \% \mathrm{Cl}$ & $n$ & $\%$ & $95 \% \mathrm{Cl}$ \\
\hline \multicolumn{10}{|l|}{$6-9$ years } \\
\hline Rural & 3221 & 4.62 & 0.47 & 59 & $1.83^{\star \star}$ & $1 \cdot 37,2 \cdot 30$ & 0 & \multicolumn{2}{|r|}{$-\dagger$} \\
\hline Urban & 3226 & 4.60 & 0.44 & 25 & 0.78 & $0.47,1.08$ & 4 & 0.12 & $0.02,0.25$ \\
\hline \multicolumn{10}{|c|}{ 10-17 years } \\
\hline Rural & 4791 & $4.62^{\star \star}$ & 0.55 & 106 & $2 \cdot 21$ & $1.80,2.63$ & 4 & 0.08 & $0.01,0.17$ \\
\hline Urban & 5196 & 4.68 & 0.54 & 120 & $2 \cdot 31$ & $1 \cdot 90,2 \cdot 72$ & 9 & 0.17 & $0.06,0.29$ \\
\hline \multicolumn{10}{|c|}{$6-17$ years } \\
\hline Rural & 8012 & $4 \cdot 62^{\star \star}$ & 0.52 & 165 & 2.06 & $1.75,2.37$ & 4 & 0.05 & $0.01,0.10^{*}$ \\
\hline Urban & 8422 & $4 \cdot 65$ & 0.51 & 145 & 1.72 & $1.44,2.00$ & 13 & 0.15 & $0.07,0.24$ \\
\hline
\end{tabular}

DM, diabetes mellitus.

${ }^{*} P<0.01$ between rural and urban; ${ }^{* *} P<0.001$ between rural and urban.

$\dagger '-$, no data.

peers $(4.68 v .4 .62 \mathrm{mmol} / 1, r 0 \cdot 055, P<0 \cdot 001)$, and rural children had a higher prevalence of IFG than their urban peers (1.83v. $0.78 \%, r_{\varphi} 0.047, P<0.001$ ) (Table 3).

\section{Influencing factors for impaired fasting g/ucose}

Table 4 shows influencing factors of IFG in adolescents. Although BMI groups and self-reported information, including intake frequencies of fruit, vegetables, carbonated beverages, meats and fried foods, sedentary time, physical activity and record of family history of diabetes were tested, only four factors were associated with IFG in adolescents, but not in children using the backward likelihood ratio method. Adolescents who reported consuming milk $<250 \mathrm{ml} / \mathrm{d}(\mathrm{OR}=1.59$, $95 \%$ CI $1.18,2 \cdot 15 ; P=0.002)$ and fried foods $\geq$ once/week $(\mathrm{OR}=1 \cdot 35,95 \% \mathrm{CI} 1 \cdot 02,1 \cdot 80 ; P=0 \cdot 037)$ had higher risk of IFG than those who reported consuming milk $>250 \mathrm{ml} / \mathrm{d}$ and fried foods < once/week. Moreover, compared with normal weight adolescents, overweight $(\mathrm{OR}=1.49,95 \%$ CI $1.01,3 \cdot 10$; $P=0.047)$ and obese adolescents $(\mathrm{OR}=1 \cdot 86,95 \%$ CI $1 \cdot 12$,
$3.10 ; P<0.001)$ were associated with higher risk of IFG. However, self-reported vigorous physical activity was associated with lower risk of IFG $(\mathrm{OR}=0.43,95 \%$ CI $0.21,0.89$; $P=0 \cdot 022$ ).

\section{Region and sex differences in factors for impaired fasting glucose}

Table 5 presents region and sex differences in potential factors for IFG. Compared with rural adolescents, more urban adolescents reported they consumed fried foods $\geq$ once/week ( $46 \cdot 3 v$. $41.3 \%, P<0 \cdot 001)$, while less urban adolescents reported they consumed milk $<250 \mathrm{ml} / \mathrm{d}(71.2 v .76 .9 \%, P<0.001)$ and performed vigorous physical activity $(4.5 v .9 .3 \%, P<0.001)$. In addition, the obesity prevalence of urban adolescents was higher than that in their rural peers $(10 \cdot 2 v \cdot 6 \cdot 5 \%, P<0 \cdot 001)$.

Compared with girls, more boys reported they consumed fried foods $\geq$ once/week ( $45 \cdot 4 v .42 \cdot 6 \%, P=0 \cdot 010$ ). Moreover, obesity prevalence in boys was significant higher than in girls $(10 \cdot 8$ v. $5.9 \%, P<0.001)$. 
Table 4. Factors analysis of impaired fasting glucose in Chinese adolescents aged 10-17 years (Numbers, odds ratios and $95 \%$ confidence intervals)

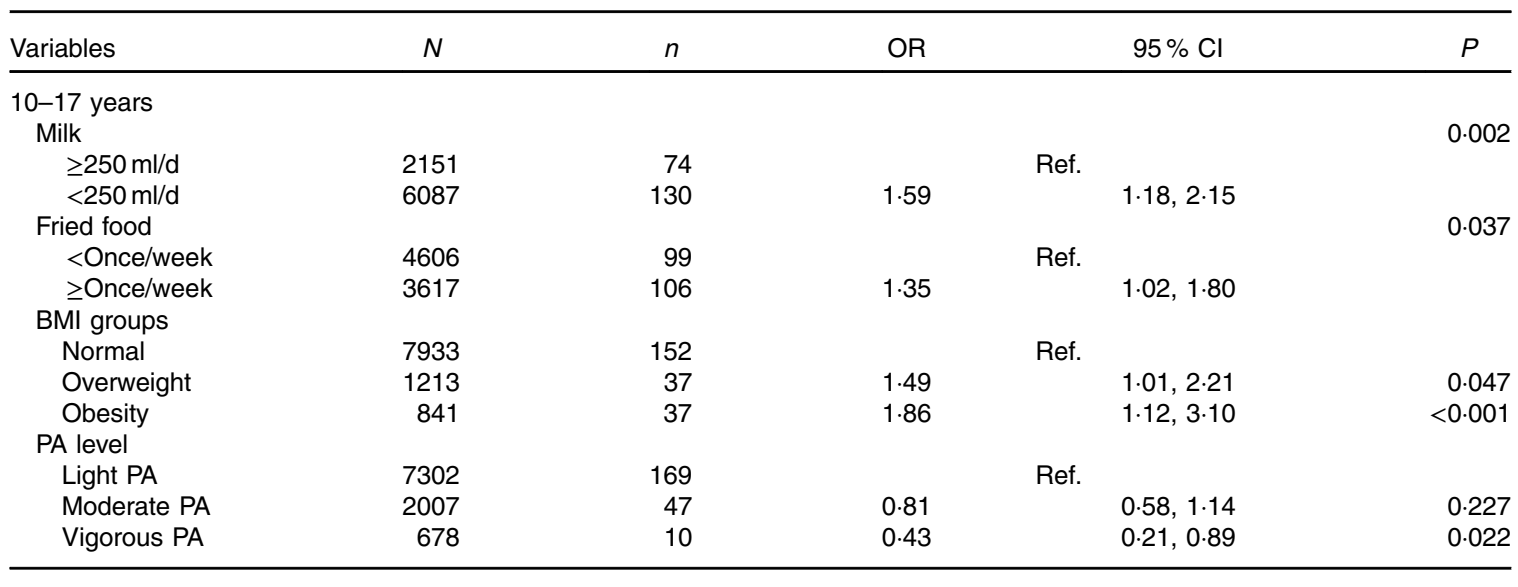

Ref., reference; PA, physical activity.

Table 5. Factors related to the region and sex disparities in impaired fasting glucose among adolescents aged 10-17 years (Numbers and percentages)

\begin{tabular}{|c|c|c|c|c|c|c|c|c|c|c|}
\hline \multirow[b]{3}{*}{ Factors } & \multicolumn{5}{|c|}{ Region } & \multicolumn{5}{|c|}{ Sex } \\
\hline & \multicolumn{2}{|c|}{ Rural } & \multicolumn{2}{|c|}{ Urban } & \multirow[b]{2}{*}{$P$} & \multicolumn{2}{|c|}{ Boys } & \multicolumn{2}{|c|}{ Girls } & \multirow[b]{2}{*}{$P$} \\
\hline & $n$ & $\%$ & $n$ & $\%$ & & $n$ & $\%$ & $n$ & $\%$ & \\
\hline Milk consumption $<250 \mathrm{ml} / \mathrm{d}$ & 2972 & 76.9 & 3115 & $71 \cdot 2$ & $<0.001$ & 3006 & $73 \cdot 1$ & 3081 & 74.7 & 0.090 \\
\hline Fried foods $\geq$ once/week & 1594 & $41 \cdot 3$ & 2023 & $46 \cdot 3$ & $<0.001$ & 1865 & $45 \cdot 4$ & 1752 & $42 \cdot 6$ & 0.010 \\
\hline BMI group & & & & & $<0.001$ & & & & & $<0.001$ \\
\hline Normal weight & 4009 & 83.7 & 3924 & $75 \cdot 5$ & & 3836 & 74.7 & 4097 & 84.5 & \\
\hline Overweight & 469 & 9.8 & 744 & 14.3 & & 747 & 14.5 & 466 & $9 \cdot 6$ & \\
\hline Obesity & 313 & 6.5 & 528 & $10 \cdot 2$ & & 555 & $10 \cdot 8$ & 286 & 5.9 & \\
\hline PA level & & & & & $<0.001$ & & & & & 0.148 \\
\hline Light PA & 3308 & 69.0 & 3994 & 76.9 & & 3717 & $72 \cdot 3$ & 3585 & 73.9 & \\
\hline Middle PA & 1037 & 21.6 & 970 & $18 \cdot 7$ & & 1071 & $20 \cdot 8$ & 936 & $19 \cdot 3$ & \\
\hline Vigorous PA & 446 & 9.3 & 232 & 4.5 & & 350 & 6.8 & 328 & 6.8 & \\
\hline
\end{tabular}

PA, physical activity.

\section{Discussion}

Using data of a national survey conducted in Chinese children and adolescents aged 6-17 years, the present study observed the prevalence of IFG and DM was 1.89 and $0 \cdot 10 \%$, respectively. Generally, boys had higher FPG concentration and IFG risk than girls, urban children and adolescents had higher FPG concentration and DM prevalence than their rural peers. This may be partly attributed to the higher obesity prevalence and unhealthy dietary behaviour in boys and those living in urban regions than those in girls and in rural regions. Regarding the limited medical resources ${ }^{(11)}$, populations with higher burden of IFG and DM should be prioritised, and interventions aimed to reduce obesity and improve dietary behaviour could be helpful to bridge these gaps.

Consistent with the previous Chinese study ${ }^{(6)}$, the prevalence of IFG (1.89\%) and DM (0.10\%) in Chinese children and adolescents was lower than those in other countries. For example, $\mathrm{Fu}$ et $a l .{ }^{(6)}$ studied diabetes in clinical settings and found the prevalence of DM was $0 \cdot 11 \%$ in Chinese children. Several surveys conducted in other countries showed that the prevalence of DM was $0.4 \%$ in Nigeria children and adolescents aged 2-19 years ${ }^{(20)}, 0 \cdot 3 \%$ in American adolescents aged 10-19 years $^{(21)}$ and $0.45 \%$ in the Saudi Arabian population aged 0-18 years $^{(22)}$. Additionally, the present study observed Chinese children and adolescents had a lower IFG prevalence than their peers from Saudi Arabia ${ }^{(22)}$ and America ${ }^{(23)}$ (1.89 v. 6.12 and $16 \cdot 1 \%$, respectively).

A significant sex difference in FPG concentration and IFG prevalence was observed in this study. Boys had a $0 \cdot 11 \mathrm{mmol} / \mathrm{l}$ higher FPG concentration than girls. Meanwhile, the prevalence of IFG and DM in boys was 1.5 and 0.6 times higher than in girls, respectively. A similar difference was also found in the Uganda study $^{(24)}$, which reported that DM prevalence in boys and girls was $1.6(95 \%$ CI 0.8, 2.6) and $1 \cdot 1$ (95\% CI 0.6, 1.7)\%, respectively. We speculated that the difference of overweight/obesity prevalence between Chinese boys and girls might contribute to the sex gap in IFG. Overweight/obesity was positively associated with IFG, and the prevalence of overweight/obesity in boys was $58 \%$ higher than in girls, which had been found in this study.

Region difference in FPG concentration and DM prevalence was found in the present study. Urban children and adolescents 
had a higher DM prevalence than their rural peers. The FPG level in urban participants was also higher than that in rural counterparts, but the difference was very small. We speculated that the differences in frequency of fried foods consumption and obesity prevalence between urban and rural children and adolescents might be associated with the region differences. We found that consuming fried foods $\geq$ once/week and overweight/obesity were positively associated with IFG, and the proportion of consuming fried foods $\geq$ once/week and overweight/obesity prevalence in urban children and adolescent was higher than in their rural peers. In addition, we observed rural children aged 6-9 years had 1.35 times higher IFG prevalence than their urban peers. Although the potential mechanism remains highly speculative, we cannot exclude that it may be associated with some of the rural children aged 6-9 years not truly fasting.

IFG is a risk state before diabetes, which is important in the prevention and control strategies for diabetes. In the present study, we found the IFG was negatively associated with milk consumption in children aged 10-17 years, which was also detected by the Health Professionals Follow-up Study ${ }^{(25)}$ and a 10-year follow-up study among 37187 women $^{(26)}$. They estimated that one serving of dairy foods daily was associated with an annual reduction in diabetes incidence of $9.0 \%$ in men and $4.0 \%$ in women. The mechanisms underlying the associations between dairy consumption and DM include the high content of Ca and vitamin D in dairy foods ${ }^{(27)}$ and the positive effect of dairy foods and $\mathrm{Ca}$ intake on weight control ${ }^{(28)}$.

In the present study, we additionally observed that fried foods consumption and obesity could raise the risk of IFG, which was also reported by other studies ${ }^{(29,30)}$. Frying is a common cooking method worldwide, which modifies both the foods composition and oils by the processes of oxidation, polymerisation and hydrogenation. With repeated use, oils deteriorate and increase amounts of cholesterol oxidation products and trans fatty acid ${ }^{(31)}$, which have been associated with insulin resistance and diabetes ${ }^{(32,33)}$. Furthermore, obesity is characterised by excess body fat, which was associated with IFG and diabetes ${ }^{(34)}$.

In addition, a strong negative association between vigorous physical activity and IFG was observed among children and adolescents aged 10-17 years. Similar association has been reported by several cross-sectional studies, longitudinal studies and meta-analyses, indicating that physical activity independent of dietary or weight loss reduces the risk of T2DM in people with prediabetes ${ }^{(35-37)}$. The mechanism behind the association may be linked with physical activity-induced improvements in glucose homoeostasis which occur through acute responses and chronic adaptations ${ }^{(38-41)}$. However, we did not observe significant association between sedentary time and IFG in the present study (OR $=0.96 ; 95 \%$ CI $0.93,1.01 ; P=0.087)$. It was inconsistent with the study of Kriska et $a l .{ }^{(42)}$, which observed overweight/obese adolescents aged 10-17 years with T2DM spent significantly more time being sedentary than their obese counterparts without T2DM $(56 \mathrm{~min} / \mathrm{d}, P<0 \cdot 001)$. We speculated that methods of collecting sedentary time between two studies might contribute to the inconsistent association. The accelerometry was used to assess the sedentary time in the study of Kriska et $a l .{ }^{(42)}$. However, the self-report questionnaire was used to collect the sedentary time in the present study. Thus, recall bias and length of sedentary bouts in the present study could be contributed to the differences ${ }^{(43)}$.

The present study had several limitations. Firstly, we cannot distinguish type $1 \mathrm{DM}$ from T2DM in this study, and the results may include both types of diabetes. Secondly, only FPG, rather oral glucose tolerance test or HbA1c, was measured. Studies found the sensitivity of intravenous fasting glucose as a screening method for DM could be relatively low, and thus, this method may not identify some individuals with impaired glucose tolerance. Thirdly, any symptomology of diabetes was not recorded in this study, such as polyuria, polydipsia and weight loss. Moreover, we did not measure the fasting insulin concentration and cannot assess the insulin resistance, such as homoeostasis model assessment-insulin resistance.

Despite those limitations, the present study using a large sample with broad representation found the prevalence of IFG and DM was still low in Chinese children. However, sex and region disparities in FPG and IFG have been observed, and interventions addressing fried foods, vigorous physical activity and obesity may contribute to bridging these gaps. Appropriate approaches should be conducted for children and adolescents with IFG or DM and prioritise interventions aimed to modify dietary behaviours and reducing burden of obesity for improving the health of Chinese children and adolescents.

\section{Acknowledgements}

The authors greatly appreciate the Educational Administration Leaderships and primary and middle school health nurses. The authors would additionally acknowledge all participants and investigators for their cooperation and efforts, especially the effort of D. M. Ma and R. Ma.

The project was supported by the Research Special Fund for Public Welfare Industry of Health (grant no. 201202010) and the Excellent Talents Fund Program of Peking University Health Science Center (BMU2017YJ002).

J. M., Y. M., J. J., J. L., X. Z., C. L., H. W., H. Z. and D. P. were co-investigators and designed the study, $\mathrm{Z}$. W. carried out the initial analysis, and Y. M. and B. D. supervised the data analysis. All authors were involved in writing the manuscript and had final approval of the submitted and published versions. Z. W. took full responsibility for the whole work.

The authors declare that there are no conflicts of interest.

\section{References}

1. Viner R, White B \& Christie D (2017) Type 2 diabetes in adolescents: a severe phenotype posing major clinical challenges and public health burden. Lancet 389, 2252-2260.

2. International Diabetes Federation (2015) IDF Diabetes Atlas, 7 th ed. Brussels: International Diabetes Federation.

3. Nadeau K \& Dabelea D (2008) Epidemiology of type 2 diabetes in children and adolescents. Endocr Res 33, 35-58.

4. Duncan GE (2006) Prevalence of diabetes and impaired fasting glucose levels among US adolescents: National Health and Nutrition Examination Survey, 1999-2002. Arch Pediatr Adolesc Med 160, 523-528. 
5. SEARCH for Diabetes in Youth Study Group, Liese AD, D'Agostino RB Jr, et al. (2006) The burden of diabetes mellitus among US youth: prevalence estimates from the SEARCH for Diabetes in Youth Study. Pediatrics 118, 15101518.

6. Fu JF, Liang L, Gong CX, et al. (2013) Status and trends of diabetes in Chinese children: analysis of data from 14 medical centers. World J Pediatr 9, 127-134.

7. Oester IM, Kloppenborg JT, Olsen BS, et al. (2016) Type 2 diabetes mellitus in Danish children and adolescents in 2014. Pediatr Diabetes 17, 368-373.

8. Smyth S \& Heron A (2006) Diabetes and obesity: the twin epidemics. Nat Med 12, 75-80.

9. American Diabetes Association (2011) Diagnosis and classification of diabetes mellitus. Diabetes Care 34, Suppl. 1, S62-S69.

10. Wu H, Zhong J, Yu M, et al. (2017) Incidence and time trends of type 2 diabetes mellitus in youth aged 5-19 years: a population-based registry in Zhejiang, China, 2007 to 2013. BMC Pediatr 17, 85

11. Zhang Y (2016) Study on urban and rural medical and health resources allocation balance in China. Med Soc 1, 7-9.

12. Chen Y, Ma L, Ma Y, et al. (2015) A national school-based health lifestyles interventions among Chinese children and adolescents against obesity: rationale, design and methodology of a randomized controlled trial in China. BMC Public Health 15, 210.

13. Craig CL, Marshall AL, Sjostrom M, et al. (2003) International physical activity questionnaire: 12-country reliability and validity. Med Sci Sports Exerc 35, 1381-1395.

14. American Diabetes Association (2012) Diagnosis and classification of diabetes mellitus. Diabetes Care 35, Suppl. 1, S64-S71.

15. Ji CY, Working Group on Obesity in China (2005) Report on childhood obesity in China (1)-body mass index reference for screening overweight and obesity in Chinese school-age children. Biomed Environ Sci 18, 390-400.

16. Li H, Zong XN, Ji CY, et al. (2010) [Body mass index cut-offs for overweight and obesity in Chinese children and adolescents aged 2-18 years]. Zhonghua Liu Xing Bing Xue Za Zhi 31, 616-620.

17. Kuruvilla S, Bustreo F, Kuo T, et al. (2016) The global strategy for women's, children's and adolescents' health (2016-2030): a roadmap based on evidence and country experience. Bull World Health Organ 94, 398-400.

18. de Onis M, Onyango AW, Borghi E, et al. (2007) Development of a WHO growth reference for school-aged children and adolescents. Bull World Health Organ 85, 660-667.

19. Brown LD, Cai TT \& Dasgupta A (2001) Interval estimation for a binomial proportion. Stat Sci 16, 101-117.

20. Agbre-Yace ML, Oyenusi EE, Oduwole AO, et al. (2015) Prevalence of diabetes mellitus among children and adolescents in the district of Abidjan in Cote d'Ivoire: a populationbased study. J Diabetes Metab Disord 15, 38.

21. Dabelea D, Mayer-Davis EJ, Saydah S, et al. (2014) Prevalence of type 1 and type 2 diabetes among children and adolescents from 2001 to 2009. JAMA 311, 1778-1786.

22. Al-Rubeaan K (2015) National surveillance for type 1, type 2 diabetes and prediabetes among children and adolescents: a population-based study (SAUDI-DM). J Epidemiol Community Health 69, 1045-1051.

23. Li C, Ford ES, Zhao G, et al. (2009) Prevalence of pre-diabetes and its association with clustering of cardiometabolic risk factors and hyperinsulinemia among U.S. adolescents: National Health and Nutrition Examination Survey 2005-2006. Diabetes Care 32, 342-347.

24. Bahendeka S, Wesonga R, Mutungi G, et al. (2016) Prevalence and correlates of diabetes mellitus in Uganda: a population-based national survey. Trop Med Int Health 21, 405-416.

25. Choi HK, Willett WC, Stampfer MJ, et al. (2005) Dairy consumption and risk of type 2 diabetes mellitus in men: a prospective study. Arch Intern Med 165, 997-1003.

26. Liu S, Choi HK, Ford E, et al. (2006) A prospective study of dairy intake and the risk of type 2 diabetes in women. Diabetes Care 29, 1579-1584.

27. Pittas AG, Lau J, Hu FB, et al. (2007) The role of vitamin D and calcium in type 2 diabetes. A systematic review and metaanalysis. J Clin Endocrinol Metab 92, 2017-2029.

28. Zemel MB, Donnelly JE, Smith BK, et al. (2008) Effects of dairy intake on weight maintenance. Nutr Metab (Lond) 5, 28

29. Cahill LE, Pan A, Chiuve SE, et al. (2014) Fried-food consumption and risk of type 2 diabetes and coronary artery disease: a prospective study in 2 cohorts of US women and men. Am J Clin Nutr 100, 667-675.

30. Alhazmi A, Stojanovski E, McEvoy M, et al. (2014) The association between dietary patterns and type 2 diabetes: a systematic review and meta-analysis of cohort studies. J Hum Nutr Diet 27, 251-260.

31. Li A, Ha Y, Wang F, et al. (2012) Determination of thermally induced trans-fatty acids in soybean oil by attenuated total reflectance Fourier transform infrared spectroscopy and gas chromatography analysis. J Agric Food Chem 60, 10709-10713.

32. de Souza RJ, Mente A, Maroleanu A, et al. (2015) Intake of saturated and trans unsaturated fatty acids and risk of all cause mortality, cardiovascular disease, and type 2 diabetes: systematic review and meta-analysis of observational studies. BMJ 351, h3978.

33. King AJ \& Priesbe TJ (2006) Concerns about methodology and use of 3,5,7-cholestatriene as a marker of oxidative stress response to "Relationship between carotid atherosclerosis and erythrocyte membrane cholesterol oxidation products in type 2 diabetic patients". Diabetes Res Clin Pract 72, 331-334.

34. Neeland IJ, Turer AT, Ayers CR, et al. (2012) Dysfunctional adiposity and the risk of prediabetes and type 2 diabetes in obese adults. JAMA 308, 1150-1159.

35. Manson JE, Nathan DM, Krolewski AS, et al. (1992) A prospective study of exercise and incidence of diabetes among US male physicians. JAMA 268, 63-67.

36. Hu FB, Manson JE, Stampfer MJ, et al. (2001) Diet, lifestyle, and the risk of type 2 diabetes mellitus in women. $N$ Engl J Med 345, 790-797.

37. Yates T, Khunti K, Bull F, et al. (2007) The role of physical activity in the management of impaired glucose tolerance: a systematic review. Diabetologia 50, 1116-1126.

38. Albright A, Franz M, Hornsby G, et al. (2000) American College of Sports Medicine position stand. Exercise and type 2 diabetes. Med Sci Sports Exerc 32, 1345-1360.

39. Goodyear LJ \& Kahn BB (1998) Exercise, glucose transport, and insulin sensitivity. Annu Rev Med 49, 235-261.

40. Ivy JL (1987) The insulin-like effect of muscle contraction. Exerc Sport Sci Rev 15, 29-51.

41. Despres JP (1997) Visceral obesity, insulin resistance, and dyslipidemia: contribution of endurance exercise training to the treatment of the plurimetabolic syndrome. Exerc Sport Sci Rev 25, 271-300.

42. Kriska A, Delahanty L, Edelstein S, et al. (2013) Sedentary behavior and physical activity in youth with recent onset of type 2 diabetes. Pediatrics 131, e850-e856.

43. de Winter M, Rioux BV, Boudreau JG, et al. (2018) Physical activity and sedentary patterns among metabolically healthy individuals living with obesity. J Diabetes Res 2018, 7496768. 